\title{
An Examination of the Construct Validity and Reliability of the Ghiselli Self-Description Inventory as a Measure of Self-Esteem
}

\author{
Charles S. Raben \\ Personnel Research and Development Center, \\ U.S. Civil Service Commission \\ Robert A. Snyder \\ The University of Alabama \\ R. Gene Hoffman \\ Indiana University-Purdue University at Indianapolis \\ James L. Farr \\ The Pennsylvania State University
}

Two studies are reported which investigated the construct validity and reliability of the Ghiselli SelfDescription Inventory as a measure of self-esteem. The first study, using a multitrait-multimethod matrix, found little evidence for the construct validity of the instrument. The second study found a significant, although low, test-retest reliability for the instrument. The degree and pattern of relationships of the instrument with other psychological measures differed for its first and second administrations. These findings are discussed relative to the continued use of the instrument in research and the general study of self-esteem in the context of organizational behavior.

In recent years, it has become increasingly common for theoretical formulations of organizational behavior to feature constructs based on self-referent attitudes (cf. Lawler, 1971, 1973; Mansfield, 1973). One of the earliest and most noteworthy of these formulations is the cognitive consistency-based theory of Korman (1970, 1976). Korman's model suggests that individuals

APPLIED YSYCHOLOGICAL MEASUREMENT

Vol. 2, No. 1 Winter 1978 pp. 73-81

(c) Copyright 1978 West Publishing Co. will engage in and find satisfying those behavioral roles which maximize their sense of cognitive balance or consistency. Although he has repeatedly found general support for the proposition that individuals will behave in ways which are consistent with their attitudes about themselves, (i.e., their operating levels of self-esteem), Korman's research evidence rests exclusively upon the apparent measurement of selfesteem as obtained by the Self-Assurance Scale of the Ghiselli (1971) Self-Description Inventory (GSDI/SA).

Recent reviews of the empirical tests of this consistency hypothesis and its various derivatives (Dipboye, 1977; Jones, 1973) indicate not only a lack of uniform support for the theory, but also an inability to eliminate self-enhancement theory as a plausible alternative explanation for the findings that have provided support. In order to help resolve these issues, Dipboye (1977) proposed an examination of the convergent and discriminant validity of the instruments purporting to measure self-esteem. He particularly recommended a study of the GSDI/SA. 
It is obvious that the equivocality evident in research of this type cannot be completely resolved when the validity and reliability of the instruments used to measure the variables of interest remain unknown. The purpose of the studies reported below was, therefore, to examine the response characteristics of the GSDI/SA and to determine if its continued use as a measure of self-esteem is warranted.

\section{Study I}

The first study was designed to investigate the convergent and discriminant validity of the GSDI/SA as evidence of its construct validity. Since any two measures may correlate highly with one another because of common method, as well as trait variance, Campbell and Fiske (1959) have suggested that the demonstration of construct validity requires that each of at least two traits be measured by at least two methods of assessment. A multitrait-multimethod matrix of the intercorrelations among the various measures can then be examined for possible evidence of convergent and discriminant validity.

In the present study alternative methods were used to measure the variables of self-esteem, personal efficacy, and achievement motivation. The various methods ${ }^{1}$ included forced-choice measures, true-false measures, Likert-type rating scales, and an actual-ideal discrepancy method of assessment.

\section{Method}

Subjects. Since the majority of Korman's research rests upon data obtained from university students, a similar population was sampled in the present study. The subjects were 78 male un-

\footnotetext{
'Strictly speaking, these different types of measures can be interpreted as involving only one method, i.e., self-report. Although measurement by truly unique methods is desirable, such data could not be obtained in either of the studies reported here.
}

dergraduate students enrolled in an introductory psychology course at a large university in the Western United States. All subjects received laboratory credit for their participation in the study.

Procedure. Students were given a packet of instruments to which they were asked to respond. The experimenter instructed each participant in the proper procedure to be followed in completing each of the measures. Upon completion, the experimenter discussed the study with each student and thanked him for his cooperation and participation.

Measures. The choice of instruments used to measure a construct was, in each case, based upon a necessary conceptual resemblance among them in tapping the construct. In the case of self-esteem, therefore, it was necessary to include instruments which purported to measure the underlying construct and to which the GSDI/SA could be compared. The instruments chosen to perform this function and which represented alternative methods of self-esteem assessment included the Coopersmith (1967) SelfEsteem Inventory (modified ${ }^{2}$ ), the Rosenberg (1965) Self-Esteem Scale, and the Sherwood (1962) Inventory of the Self-Concept. In each instance, the construct of self-esteem is interpreted as a generalized, global perception of one's self-worth.

Personal efficacy was the second variable chosen for study. This construct has traditionally been defined as a feeling of mastery: it is a perception of self that focuses upon control over one's self, one's future, and one's physical and social environments. Consequently, individuals with low personal efficacy are more likely than individuals with high personal efficacy to perceive an external locus of control and to conform to the opinion of others in evaluating a task

\footnotetext{
${ }^{2}$ Since the Inventory was originally used to assess self-esteem in a younger age group, certain words in some of the items were changed to make referents more meaningful to college age students.
} 
or situation, rather than relying on their own judgment or self-perceptions. In accordance with these conceptions, the instruments included here were measures of personal competence (Campbell, Converse, Miller, \& Stokes, 1960), locus of control (Rotter, 1966), and social desirability (Crowne \& Marlowe, 1960).

Note that such perceptions of control should obviously contribute to more global and enduring perceptions of worthiness. Given this theoretical relationship between personal efficacy and self-esteem, the present study provided a powerful test of the validity of the GSDI/SA by heightening the criterion levels which must be satisfied in order to demonstrate discriminant validity.

Achievement motivation was chosen as the third construct in the study in order to examine its relationship to both personal efficacy and self-esteem. Focusing on a motivational disposition rather than an attitude toward the self, this construct may be construed as a desire for the status, prestige, and recognition associated with accomplishment. Like personal efficacy, achievement motivation is thought to be related to perceptions of chronic self-esteem. For example, some researchers (Raben \& Klimoski, 1973; Korman, 1968) have suggested the possibility that high self-esteem individuals are more achievement-oriented as a result of the value which is attributed to success over a period of time. In order to further explore this possibility, alternative measures of achievement motivation were included here: the Achievement Scale of the Edwards Personal Preference Schedule (EPPS; Edwards, 1959) and the Achievement (Independence) Scale of the California Psychological Inventory (CPI; Gough, 1957).

Once selected, the instruments were organized according to their respective methods of assessment. Method I consisted of instruments using forced-choice response alternatives. Method II measured the various traits using a truefalse or similarly dichotomous format. Instruments grouped under Method III share the common use of rating scales. Method IV consisted of a measurement procedure in which a discrepancy score is derived by obtaining the difference between the subject's "actual" standing and some preferred or "ideal" standing on the variable of interest. However, since (1) no measure of achievement motivation was available that used a rating scale method of assessment (Method III) and (2) Method IV was not relevant to the measurement of personal efficacy or achievement motivation, it was not possible to complete the entire matrix. Instead of 12 entries (three traits measured by each of four methods), only nine measures were included.

\section{Results}

The multitrait-multimethod matrix of intercorrelations is presented in Table 1 . The validity coefficients are represented by the underlined diagonal values. Solid lines surround the heterotrait-monomethod triangles, and the heterotraitheteromethod triangles are enclosed by broken lines.

Convergent validity. Evidence for convergent validity may be determined by examining the underlined diagonal entries which represent the correlations of different methods measuring the same trait. These validity coefficients should be significantly different from zero and of sufficient size to encourage further examination. It is evident from Table 1 that scores on the Coopersmith, Rosenberg, and Sherwood measures of self-esteem were highly intercorrelated and shared a sizable proportion of common variance. While the Ghiselli Self-Description Inventory Self-Assurance Scale did correlate signiticantly with the Coopersmith and Rosenberg measures, the proportion of variance shared with each of them was much less than that evident among the previous three. The GSDI/SA did not correlate at all with the Sherwood instrument. When the correlation of the GSDI/SA with another measure of self-esteem was compared to that respective instrument's correlation with the remaining measures, five of the six possible correlation comparisons were found to be 


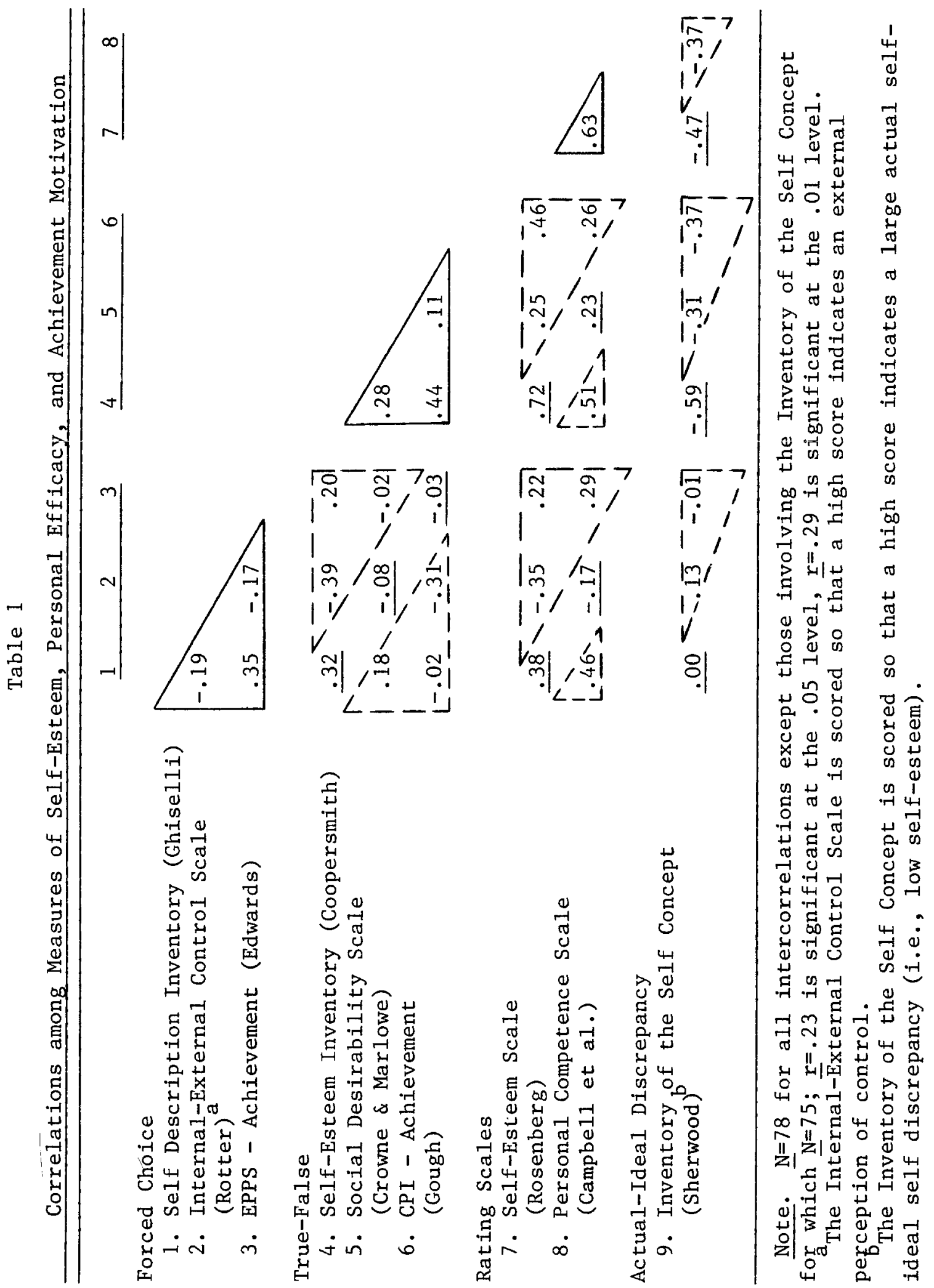


significantly different at at least the .02 level. These data, therefore, provide only weak support for the convergent validity of GSDI Self-Assurance Scale as a measure of self-esteem.

Discriminant validity. Three criteria must be satisfied in providing evidence for discriminant validity. The first is that an instrument's validity coefficients be higher than its correlations with other variables in the heterotraitheteromethod (broken line) triangles. Secondly, an instrument's validity coefficients must also be higher than its correlations with other traits measured by the same method as included in the heterotrait-monomethod (solid line) triangles. The final criterion to be satisfied is that the same pattern of trait interrelationships occur in all the heterotrait triangles.

With the exception of the Ghiselli instrument, the self-esteem measures were able to satisfy the first criterion for discriminant validity. The Ghiselli instrument was unable to satisfy the criterion because its correlation with the Campbell et al. measure was larger than any of its correlations with other measures of self-esteem.

The GSDI/SA was also unable to satisfy the second criterion for discriminant validity since its correlation with the EPPS measure of achievement motivation was higher than two of its three validity coefficients. It is difficult to confidently assess how well the remaining selfesteem measures satisfied this criterion because of missing correlations. Available data indicated that the Coopersmith scale was able to satisfy the criterion, whereas the Rosenberg measure was not. A complete absence of data precludes the possibility of determining the extent to which the Sherwood instrument satisfied the criterion.

Variable patterns of trait relationships within each of the heterotrait-heteromethod triangles made it impossible to absolutely satisfy the third criterion for discriminant validity. At a more general level, however, it is possible to examine the consistency of these relationships, regardless of method. In this context, the data suggest that the direction and magnitude of the relationships among the trait measures were indeed fairly consistent, with the possible exception, once again, of the Ghiselli instrument. The Coopersmith and Rosenberg measures both correlated similarly and significantly with the Rotter (-.39 and -.35), Crowne-Marlowe (.28 and .25), and Campbell et al. (-.51 and .63) measures. Except for a relatively weaker relationship with the Rotter measure, a similar pattern of correlations also existed for the Sherwood instrument (.13, -.31 , and -.37). The GSDI/SA was similar to the other self-esteem measures in the direction of its relationships to the Rotter, Crowne-Marlowe, and Campbell et al. instruments; however, its only significant relationship was with the Campbell et al. measure. The Ghiselli instrument was also unlike the other self-esteem measures in its relationship to achievement motivation. The Coopersmith and Rosenberg measures were, again, strikingly similar in their relationships to the EPPS (.20 and .22) and CPI (.44 and .46). The Sherwood instrument, too, correlated significantly with the CPI $(-.37)$, despite the lower absolute size of the relationship. The correlation between the Sherwood and EPPS measures revealed the absence of any relationship. In contrast to these observations, the data indicated that the Ghiselli instrument was more strongly related to the EPPS than any of the other self-esteem measures and had practically no relationship to the CPI.

\section{Study II}

As part of a larger research project, the second study examined the test-retest reliability of the Ghiselli Self-Description Inventory SelfAssurance Scale and further investigated both the nature and reliability of its empirical relationships to measures of other conceptually related variables. A determination of reliability for the GSDI/SA is of obvious importance in fully appreciating any possible theoretical relationship between the GSDI/SA as a measure of selfesteem and any other variables to which self-esteem may be related. Hypothesized relationships 
between self-esteem and other variables cannot be sufficiently determined when such relationships are examined with instruments of unknown or, perhaps, questionable response characteristics. The growing popularity of self-esteem and personal competence as moderating variables in research strengthens these concerns.

Although not a purely ipsative measure, the Ghiselli Self-Description Inventory does possess ipsative properties. Since there is a problem estimating the internal consistency of such measures because of a structural interdependence among the scales (cf. Hicks, 1970), no attempt will be made to determine this type of reliability for the GSDI. Rather, the present study will focus on the test-retest reliability of a single scale (Self-Assurance) and thus avoid the problems associated with ipsative measures. Moreover, since Korman used only the Self-Assurance Scale of the GSDI and subsequently treated it as an independent, normative measure of self-esteem, it is more appropriate to examine its testretest reliability than to examine its relationship to other unused scales of the GSDI.

\section{Method}

Subjects. As in the previous research, university students were again chosen to serve as participants in the study. Subjects were as many as 80 undergraduates enrolled in an industrial psychology course at a large university in the Eastern United States. All subjects participated voluntarily and received no formal credit for their participation in the study.

Procedure. The experimenter, during a regularly scheduled class meeting, asked for volunteers to participate in a study intended to examine the relationships among various personality inventories. Students were told that the study consisted of two phases approximately six weeks apart. Students who volunteered were then administered the Ghiselli Self..Description Inventory, The Rotter Internal-External Control Scale, and the Tennessee Self-Concept Scale (Fitts, 1965). The same class was administered the Ghiselli instrument again and the Campbell et al. Personal Competence Scale six weeks later.

Besides deriving a self-esteem score with the Self-Assurance Scale of the GSDI, the Need Achievement Scale of that instrument was also scored to derive a measure of achievement motivation. The relationship of these two scales to one another introduces the problem discussed earlier concerning a structural interdependence among scales of an ipsative measure. Scale intercorrelations are likely to reflect this structural arrangement and imply conceptual relationships which may not actually exist. Consequently, the present study only examined the relationships among discrete instruments and the respective underlying traits being measured by each.

\section{Results}

The intercorrelations among the various measures are presented in Table 2 . The data indicated a statistically significant, although low, test-retest reliability for both the Self-Assurance and Need Achievement Scales of the GSDI. It was also evident that the relationship of the GSDI/SA to each of the other instruments differed in each of its two administrations, with the higher correlations occurring when the instruments were administered at the same time. The GSDI/SA was significantly related to the Internal-External Control Scale in the first administration, but not in the second, and the respective correlations differed substantially; similar results were obtained between the GSDI/SA and the Tennessee Self-Concept Scale. Whereas the correlations of the GSDI/SA and the Personal Competence Scale remained significant across administrations, there was, again, a shift in the magnitude of the relationship.

Looking only at the relationship between the GSDI/SA and the Tennessee Self-Concept Scale, it was clear that neither correlation from either administration was as high as one would expect between two measures of self-esteem. The Tennessee Self-Concept Scale was not similarly correlated with either administration of the Need Achievement Scale of the GSDI. 


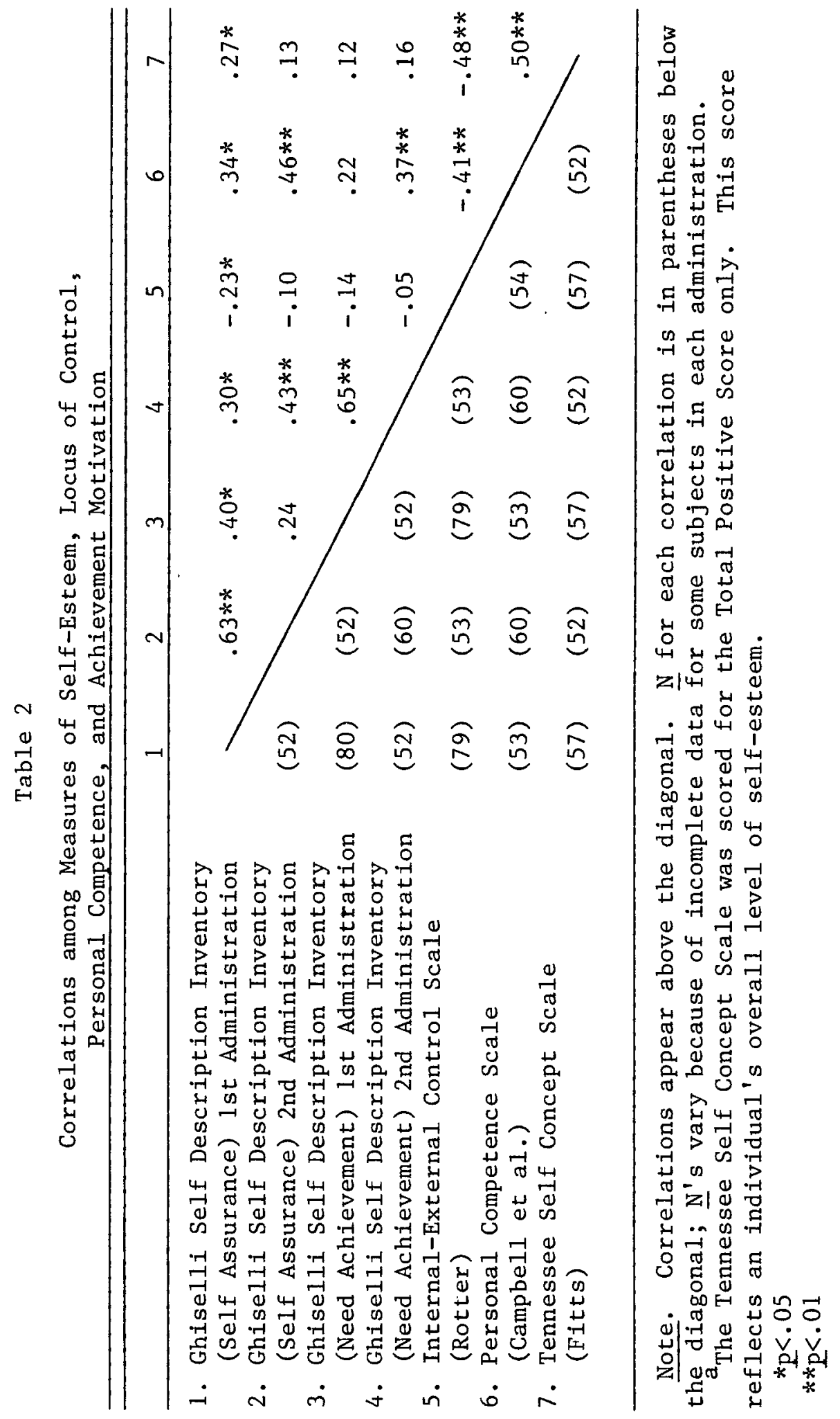




\section{Discussion}

The two studies reported here appear to raise some doubts and to suggest qualifications about the Self-Assurance Scale of the Ghiselli Self-Description Inventory as a measure of self-esteem. While the data are not overwhelming in suggesting that the instrument be abandoned, the data do suggest that researchers at least complement its use with other measures of known and acceptable response characteristics. Only in this way can the actual moderating effects of self-esteem and the power of the self-consistency model be established. Furthermore, the addition of other measures will help clarify what the GSDI/SA actually is measuring and thus enable researchers to better understand the research evidence presented by Korman.

In the first study reported, marginal validity coefficients made it difficult for the GSDI/SA to satisfy established criteria for both convergent and discriminant validity. Additional data from the second study further weakened the case for the construct validity of the instrument. It is worth noting that this analysis of the GSDI/SA rests on the apparent assumption that the other self-esteem measures are, indeed, converging on trait variance and not on method variance. While it is certainly possible that these methods share some degree of common non-trait variance, the fact remains that the Ghiselli instrument is not among them. These differences in response characteristics between the GSDI/SA and the remaining self-esteem measures may well be responsible for the equivocality Dipboye (1977) found among studies examining Korman's consistency hypotheses, where different instruments were used to measure self-esteem.

The second study provided important data concerning the reliability of GSDI/SA. Not only was the test-retest reliability coefficient lower than might be expected for such a variable, but the GSDI/SA was also unable to correlate consistently with other measures included in the study. These shifts in correlation, which in some cases meant the difference between the signifi- cance or nonsignificance of the relationship, are of obvious and critical importance to researchers. This is particularly true of studies that attempt to manipulate and assess the effects of factors influencing self-esteem.

These results raise doubts about some of the research findings derived from studies in which the GSDI/SA was used as the sole measure of self-esteem. It is certainly possible that some other construct may actually have been responsible for findings fallaciously attributed to self-esteem. Furthermore, it is equally important that researchers also reconsider those areas of study that eliminated self-esteem as a relevant expanatory variable.

Many of the comments made thus far about the GSDI/SA, particularly those surrounding its construct validity, have been made relative to other self-esteem measures and their respective characteristics as measurement instruments. Part of the difficulty in investigating the GSDI/SA as an illustrative and representative measure of self-esteem has been the conceptual distinction of the construct itself as measured by any of the instruments. The data reported in each of the two studies strongly suggest that selfesteem shares sizeable proportions of common variance with locus of control, personal competence, and achievement motivation. Clearly the construct of self-esteem needs to be further understood if the characteristics of the instruments designed to measure it are to be truly appreciated.

Despite the empirical difficulties associated with its measurement, self-esteem remains logically important to both the theory of organizational behavior and its practice. Individual perceptions of self are important to determinations of work motivation and performance. Moreover, organizational task requirements, and the performance opportunities they represent, are likely contributors to personal perceptions of competence and ability. Clearly, a need exists for the systematic study of self-esteem in the context of work behavior. A delineation of these dynamics, derived through research, is critical to a more 
complete appreciation of the interaction that occurs between the individual and the organization.

\section{References}

Campbell, A., Converse, P. E., Miller, W. E., \& Stokes, D. E. The American voter. New York: Wiley, 1960.

Campbell, D. T., \& Fiske, D. W. Convergent and discriminant validation by the multitrait-multimethod matrix. Psychological Bulletin, 1959, 56. 81-105.

Coopersmith, S. The antecedents of self-esteem. San Francisco: Freeman, 1967.

Crowne, D., \& Marlowe, D. The approval motive. New York: Wiley, 1964.

Dipboye, R. L. A critical review of Korman's self-consistency theory of work motivation and occupational choice. Organizational Behavior and $\mathrm{Hu}$ man Performance, 1977, 18, 108-126.

Edwards, A. L. Manual for the Edwards Personal Preference Schedule. New York: Psychological Corporation, 1959.

Fitts, W. H. Manual for the Tennessee Self-Concept Scale. Nashville: Counseler Recordings and Tests, 1965.

Ghiselli, E. E. Explorations in managerial talent. Pacific Palisades, CA: Goodyear, 1971.

Gough, H. G. The California Psychological Inventory Manual. Palo Alto, CA: Consulting Psychologists Press, 1957.

Hicks, L. E. Some properties of ipsative, normative, and forced-choice normative measures. Psychological Bulletin, 1970, 74, 167-184.

Jones, S. C. Self and interpersonal evaluations: Esteem theories versus consistency theories. Psy- chological Bulletin, 1973, 79, 185-199.

Korman, A. K. Task success, task popularity, and self-esteem as influences on task liking. Journal of Applied Psychology, 1968, 52, 484-490.

Korman, A. K. Toward an hypothesis of work behavior. Journal of Applied Psychology, 1970, 54. $31-41$.

Korman, A. K. Hypothesis of work behavior revisited and an extension. Academy of Management Review, 1976, 1, 50-63.

Lawler, E. E. Pay and organizational effectiveness: $A$ psychological view. New York: McGraw-Hill, 1971.

Lawler, E. E. Motivation in work organizations. Monterey, California: Brooks/Cole, 1973.

Mansfield, R. Self-esteem, self-perceived abilities, and vocational choice. Journal of Vocational Behavior, 1973, 3, 433-441.

Raben, C. S., \& Klimoski, R. J. The effects of expectations upon task performance as moderated by levels of self-esteem. Journal of Vocational Behavior, 1973, 3, 475-483.

Rosenberg, M. Society and the adolescent self-image. Princeton, NJ: Princeton University Press, 1965.

Rotter, J. B. Generalized expectancies for internal versus external control of reinforcement. Psychological Monographs, 1966, 80 (Whole No. 609), 1-28.

Sherwood, J. J. Self-identity and self-actualization: $A$ theory and research. Unpublished doctoral dissertation, University of Michigan, 1962.

\section{Author's Address}

Charles S. Raben, Personnel Research and Development Center, U.S. Civil Service Commission, $1900 \mathrm{E}$ St., NW, Washington, DC 20415 